\title{
PENGARUH ORIENTASI KEWIRAUSAHAAN DAN ORIENTASI BEKELANJUTAN TERHADAP KEWIRAUSAHAAN BERKELANJUTAN DENGAN KEWIRAUSAHAAN BRICOLAGE SEBAGAI MEDIASI PADA UKM DI INDONESIA
}

\author{
Fiera Adeline dan Franky Slamet \\ Program Studi S1 Manajemen Fakultas Ekonomi \& Bisnis Universitas Tarumanagara, Jakarta \\ Fiera.115170014@stu.untar.ac.id \\ frangkys@fe.untar.ac.id
}

\begin{abstract}
This study aims to determine the interaction of entrepreneurial orientation and sustainable orientation towards sustainable entrepreneurship with bricolage entrepreneurship as a mediation for SMEs in Indonesia. The population in this study were 190 respondents who were owners, managers or executives of SMEs in Indonesia. Sampling in this study using nonprobability sampling. The sampling technique in this study is convenience sampling. Data was obtained by distributing questionnaires using google form which was then processed using SmartPLS 3.3.2. The results show that entrepreneurial orientation, sustainable orientation, and entrepreneurial bricolage have a positive effect on sustainable entrepreneurship in Indonesia. Meanwhile, entrepreneurial bricolage has a positive effect in mediating entrepreneurial orientation and sustainable orientation towards sustainable entrepreneurship in Indonesia partially but not significantly.
\end{abstract}

Keywords : Entrepreneurial Orientation, Sustainability Orientation, SMEs, Entrepreneurial Bricolage, Sustainable Entrepreneurship

Abstrak : Penelitian ini bertujuan untuk mengetahui pengaruh orientasi kewirausahaan dan orientasi berkelanjutan terhadap kewirausahaan berkelanjutan dengan kewirausahaan bricolage sebagai mediasi pada UKM di Indonesia. Populasi pada penelitian ini adalah 190 responden yang merupakan pemilik, manajer atau eksekutif UKM yang terdapat di Indonesia. Pengambilan sampel pada penelitian ini menggunakan non-probability sampling. Teknik pemilihan sampel dalam penelitian ini adalah convenience sampling. Data diperoleh dengan menyebarkan kuesioner menggunakan google form yang kemudian diolah menggunakan SmartPLS 3.3.2. Hasil penelitian menunjukkan bahwa orientasi kewirausahaan, orientasi berkelanjutan, dan kewirausahaan bricolage berpengaruh positif terhadap kewirausahaan berkelanjutan di Indonesia. Sedangkan, kewirausahaan bricolage berpengaruh positif dalam memediasi orientasi kewirausahaan dan orientasi berkelanjutan terhadap kewirausahaan berkelanjutan di Indonesia secara partial namun tidak signifikan.

Kata Kunci : Orientasi Kewirausahaan, Orientasi Berkelanjutan, UKM, Kewirasuahaan Bricolage, dan Kewirausahaan Berkelanjutan 


\section{LATAR BELAKANG}

Kewirausahaan berkelanjutan merupakan spin-off dari pembangunan berkelanjutan. (Crals \& Vereeck, 2004). Kewirausahaan berkelanjutan difokuskan pada pelestarian alam, penunjang kehidupan, dan komunitas dalam mengejar peluang yang dirasakan untuk mewujudkan masa depan produk, proses, dan layanan untuk mencapai keuntungan. (Shepherd, 2011). Kewirausahaan berkelanjutan juga dapat didefinisikan sebagai memulai usaha yang menguntungkan dan didasarkan pada produk atau jasa yang memperhatikan manfaat lingkungan dan melestarikan budaya (IwanPrasodjo, Rita Amelinda, 2019).

Pemerintah mengakui bahwa usaha kecil dan menengah (UKM) dapat menjadi pendorong utama pertumbuhan ekonomi (Rahman et al., 2014). UKM membantu mengurangi pengangguran di Indonesia karena UKM menciptakan lapangan pekerjaan sendiri dengan cara membuka usaha (Silviasih et al., 2016). Badan Pusat Statistik (BPS) mencatat jumlah pengangguran di Indonesia mencapai 9,77 juta orang pada Agustus 2020. Kepala BPS, Suhariyanto mengungkapkan tingkat pengangguran terbuka (TPT) pada Agustus 2020 naik menjadi 7,07\%.

Penting untuk mengidentifikasi bagaimana UKM memanfaatkan sumber daya yang terbatas untuk mencapai keuntungan ekonomi tanpa merusak lingkungan dan menimbulkan masalah di dalam masyarakat (Hooi, 2016). UKM biasanya mewakili sekitar 95\% sektor swasta perusahaan di sebagian besar negara modern, dan merupakan bagian utama dari semua aktivitas ekonomi. Selain itu juga UKM menjadi sarana inovasi dan perubahan dalam sektor bisnis (Schaper, 2002). Sebagian besar UKM belum memiliki pemahaman mengenai pembangunan berkelanjutan. Oleh karena itu, penting untuk memahami konsep pembangunan berkelanjutan (Moorthy et al., 2012).

Kewirausahaan yang berkelanjutan tidak hanya menciptakan produk atau layanan tetapi juga mementingkan komitmen dan kesetaraan lingkungan (IwanPrasodjo, Rita Amelinda, 2019). Oleh karena itu, konsep kewirausahaan berkelanjutan bertujuan untuk mengejar tujuan triple bottom line yaitu ekonomi, sosial dan ekologi, sedangkan kewirausahaan sosial mengejar tujuan double bottom line yaitu sosial dan ekonomi (Belz \& Binder, 2015). Menciptakan kewirausahaan berkelanjutan yang sukses membutuhkan wirausaha yang inovatif, proaktif, dan berani mengambil risiko. Karakteristik ini disebut orientasi kewirausahaan (Miller, 1983).

Orientasi kewirausahaan juga sangat penting untuk kesuksesan UKM (Gundry et al., 2011). Orientasi kewirausahaan mencerminkan kecenderungan perusahaan untuk terlibat dalam perilaku inovatif, berani mengambil risiko dan proaktif untuk mengalahkan pesaing (Utama, L. and J.K., 2017). Pengaruh Kreatifitas Terhadap Kinerja Usaha Dengan Orientasi Kewirausahaan Sebagai Mediasi Pada Wirausaha di ITC Cempaka Mas. Conference on Managemant and Behavioral Studies. http://cmbs.untar.ac.id/images/prosiding/2017/p/Louis-utama-dan-jeremy-kristantonadi.pdf. Diakses Juni, 2020.. Orientasi kewirausahaan biasanya mengacu pada sejauh mana organisasi berwirausaha dalam rencana dan kegiatannya serta mencakup proses, struktur, dan perilaku organisasi (Stam \& Elfring, 2008). Orientasi kewirausahaan juga harus memberikan penekanan dalam menanggapi skenario pasar yang berubah dengan memanfaatkan peluang baru yang tersedia (Anderson et al., 2009).

Dacko et al. (2013) mengemukakan bahwa orientasi berkelanjutan mengarah pada inovasi dalam perusahaan yang menjalankan bisnis berkelanjutan. Kuckertz dan Wagner (2010) juga berpendapat bahwa individu dengan orientasi berkelanjutan cenderung lebih tinggi melihat peluang kewirausahaan. Pengusaha yang berorientasi berkelanjutan akan mengejar peluang yang 
menghasilkan manfaat. Dikatakan juga bahwa orientasi berkelanjutan berdampak pada kewirausahaan berkelanjutan.

Philip dan Tracey (2007) telah mempertimbangkan bahwa kewirausahaan bricolage sebagai proses transformatif yang dapat membantu menciptakan kewirausahaan berkelanjutan. Bricolage membahas masalah yang sedang berlangsung atau perkembangan baru dalam masalah dengan cara baru dan inovatif (Gundry et al., 2011). Dalam kewirausahaan, bricolage diartikan sebagai menggunakan apa yang sudah ada untuk berbuat baik atau menciptakan sesuatu dari ketiadaan (Baker dan Nelson, 2005). Perusahaan dengan sumber daya terbatas dapat mencapai lebih banyak inovasi jika menerapkan bricolage lebih selektif. Perilaku bricolage yang ditanamkan dalam diri wirausaha diharapkan dapat berperan penting dalam mencapai kewirausahaan yang berkelanjutan (Senyard et al., 2014).

\section{KAJIAN TEORI}

Teori pandangan berbasis sumber daya adalah teori yang berpengaruh untuk mengetahui bagaimana keunggulan kompetitif dalam perusahaan dapat dicapai dan bagaimana keuntungan itu bisa dipertahankan dari waktu ke waktu (Wernerfelt, 1984). Teori pandangan berbasis sumber daya berfokus pada jenis sumber daya perusahaan seperti keunikan dan kekritisan yang membantu untuk mendapatkan keunggulan kompetitif di pasar dengan cara yang berkelanjutan (Hooi et al, 2016). Teori ini juga diterapkan untuk usaha start up dan perusahaan yang sudah besar (Kellermanns et al., 2014).

Penrose (1959) mendefinisikan sumber daya sebagai hal fisik yang dibeli, disewakan, atau diproduksi oleh perusahaan untuk digunakan sendiri, dan orang yang dipekerjakan dengan persyaratan menjadi bagian efektif dari perusahaan (Penrose, 1959). Lebih dari 50 tahun para peneliti membangun wawasan Penrose, mereka berfokus pada "sumber daya strategis" (Amit et al., 1993).

Sumber daya strategis merupakan (1) sumber daya yang memiliki nilai, sehingga dapat dimanfaatkan untuk meningkatkan nilai pelanggan; (2) sumber daya yang jarang terjadi, sehingga pesaing tidak dapat memiliki akses ke sumber daya yang sama untuk bersaing memperebutkan nilai; dan (3) sumber daya yang sulit untuk diganti atau ditiru, sehingga memungkinkan perusahaan untuk tetap berada di depan pesaing (Barney, 1991).

\section{Keterkaitan antar variabel}

\section{Orientasi Kewirausahaan dengan Kewirausahaan Bricolage}

Perusahaan harus bergantung pada orientasi kewirausahaan untuk menjadi inovatif dalam menciptakan produk baru dan juga bergantung pada kewirausahaan bricolage untuk menciptakan sesuatu dari sumber daya yang ada karena orientasi kewirausahaan mendorong ide-ide positif yang mempengaruhi kewirausahaan bricolage sebagai sarana untuk mengembangkan kegiatan yang inovatif (Gundry et al., 2014).

\section{Orientasi Berkelanjutan dengan Kewirausahaan Bricolage}

Pengusaha yang berorientasi pada berkelanjutan harus terlibat dalam kewirausahaan bricolage untuk menciptakan solusi baru sehingga perusahaan dapat mencapai keunggulan yang kompetitif (Hooi et al., 2016). 


\section{Kewirausahaan Bricolage dengan Kewirausahaan Berkelanjutan}

Suatu perusahaan dapat memperoleh penjualan yang baik dan pangsa pasar yang tinggi ketika sumber daya yang terdapat di perusahaan tersebut mendukung strategi diferensiasi dan perilaku kewirausahaan bricolage membantu dalam mencapai keunggulan kompetitif dengan tetap memperhatikan aspek lingkungan, sosial, dan ekonomi (Chandler dan Hanks, 1994).

\section{Orientasi Kewirausahaan dengan Kewirausahaan Berkelanjutan melalui Kewirausahaan Bricolage}

Orientasi kewirausahaan memanfaatkan kewirausahaan bricolage dalam mengeksploitasi peluang bisnis baru untuk kewirausahaan berkelanjutan. Kewirausahaan berkelanjutan sangat mempengaruhi perusahaan melalui tujuan dan preferensi pribadi wirausaha sehingga tercermin dalam tujuan perusahaan. Oleh karena itu, kewirausahaan berkelanjutan berkaitan dengan inovatif perusahaan yang memasok produk bermanfaat bagi lingkungan dan sosial dengan potensi untuk mempengaruhi sebagian besar pasar (Schaltegger dan Wagner, 2011).

\section{Orientasi Berkelanjutan dengan Kewirausahaan Berkelanjutan melalui Kewirausahaan Bricolage}

Kewirausahaan berkelanjutan merupakan proses menemukan, mengevaluasi, dan mengeksploitasi peluang ekonomi yang terdapat dalam kegagalan pasar yang mengurangi keberlanjutan, termasuk yang relevan dengan lingkungan. Oleh karena itu, untuk mencapai keberlanjutan dan kewirausahaan lingkungan terletak pada bagaimana cara mengatasi hambatan pasar secara efisien untuk sumber daya lingkungan (Dean dan McMullen, 2007).

Berdasarkan keterkaitan antar variabel tersebut di atas, maka model penelitian yang dibuat adalah sebagai berikut:

$\mathrm{H} 4$

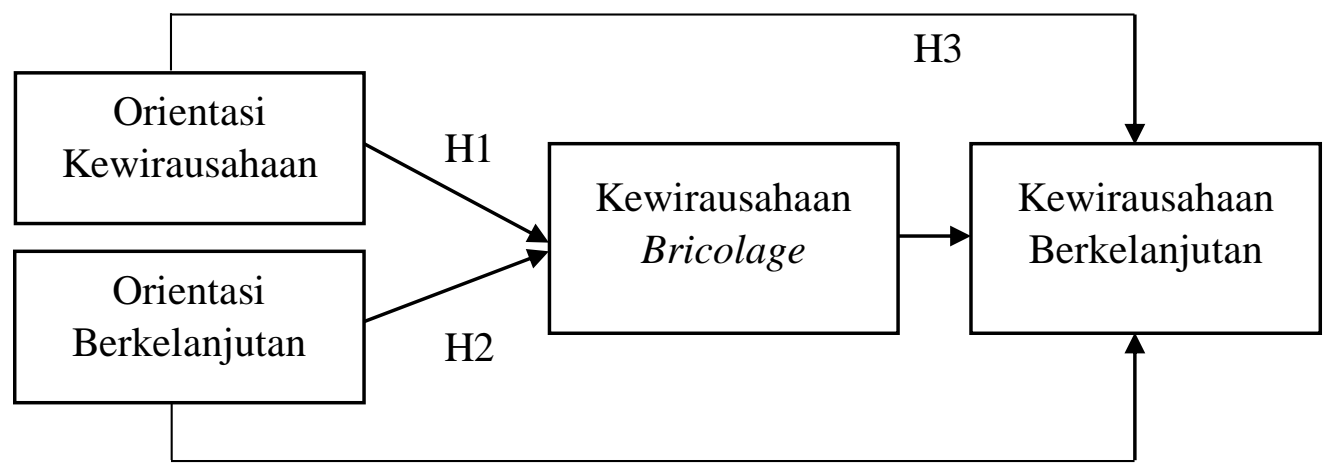

H5

Berdasarkan kerangka pemikiran dan model penelitian di atas, dirumuskan hipotesis penelitian sebagai berikut :

H1: Terdapat pengaruh positif antara orientasi kewirausahaan terhadap kewirausahaan bricolage

$\mathrm{H} 2$ : Terdapat pengaruh positif antara orientasi berkelanjutan terhadap kewirausahaan bricolage

H3: Terdapat pengaruh positif antara kewirausahaan bricolage terhadap kewirausahaan berkelanjutan 
H4: Terdapat pengaruh positif antara orientasi kewirausahaan dan kewirausahaan berkelanjutan dimediasi oleh kewirausahaan bricolage

H5: Terdapat pengaruh positif antara orientasi berkelanjutan dan kewirausahaan berkelanjutan dimediasi oleh kewirausahaan bricolage

\section{METODE PENELITIAN}

Penelitian ini menggunakan penelitian deskriptif. Menurut Sekaran \& Bougie (2016) penelitian deskriptif digunakan untuk mengumpulkan data mengenai orang, organisasi, produk, peristiwa, atau situasi. Desain penelitian deskriptif memiliki dua metode pengumpulan data, yaitu cross-sectional design dan longitudinal design. Pada penelitian ini, metode yang digunakan adalah cross-sectional design karena pengumpulan data hanya dilakukan sekali pada waktu tertentu.

. Populasi yang digunakan dalam penelitian ini adalah UKM yang beroperasi di Indonesia. Sedangkan sampel dari penelitian ini adalah pemilik, manajer atau eksekutif dari UKM yang terdapat di Indonesia. Teknik pengambilan sampel yang digunakan adalah non-probability sampling karena tidak semua elemen memiliki peluang yang diketahui atau ditentukan sebelumnya untuk dipilih sebagai sampel dan teknik pemilihan sampel yang digunakan adalah convenience samplimg agar pengumpulan data dapat dilakukan dengan mudah dan cepat. Sampel yang digunakan dalam penelitian ini adalah sebanyak 190 sampel.

Deskripsi responden yang terkumpulkan yaitu responden kelamin wanita ada sebanyak 100 orang (52,6\%), responden usia kurang dari 25 tahun sebanyak 65 orang $(34,2 \%)$, responden yang berdomisili di Jakarta sebanyak 107 orang (56,3\%), responden yang memiliki karyawan sebanyak kurang dari 30 orang adalah 131 orang $(68,9 \%)$, responden yang memiliki pendapatan kurang dari Rp. 200.000.000 sebanyak 102 orang (53,7\%), responden yang mempunyai usaha kurang dari 10 tahun sebanyak 155 orang $(81,6 \%)$, responden yang memiliki bidang usaha kuliner sebanyak 77 orang $(40,5 \%)$.

\section{Hasil dan Pembahasan}

\section{Hasil Analisis Validitas}

Hasil analisis Convergent Validity pada variabel kewirausahaan berkelanjutan, orientasi kewirausahaan, orientasi berkelanjutan, dan kewirausahaan bricolage memenuhi syarat karena Nilai Average Variance Extracted (AVE) lebih tinggi dari 0,50.

Hasil analisis Discriminant Validity pada variabel kewirausahaan berkelanjutan, orientasi kewirausahaan, orientasi berkelanjutan, dan kewirausahaan bricolage memenuhi syarat karena nilai loadings pada indikator lebih besar dibandingkan nilai indikator loadings dari variabel lainnya dan Discriminant Validity (Analisis Fornell-Larcker) berdasarkan kalkulasi aplikasi SmartPLS, seluruh indikator telah memenuhi kriteria fornell-larcker, nilai AVE masing-masing konstruk lebih besar dari nilai korelasi antara konstruk

\section{Hasil Analisis Reliabilitas}

Hasil uji reliabilitas menunjukkan bahwa semua variabel kewirausahaan berkelanjutan, orientasi kewirausahaan, orientasi berkelanjutan, dan kewirausahaan bricolage dinyatakan reliable 
karena Cronbach's Alpha dan Composite Reliability lebih besar dari 0,7 sehingga dapat dikatakan sudah memenuhi syarat

\section{Koefisien determinasi $\left(\mathbf{R}^{2}\right)$}

Variabel oreintasi kewirausahaan dan orientasi berkelanjutan memiliki pengaruh terhadap kewirausahaan bricolage sebesar 81,3\%, sedangkan sisanya 18,7\% dipengaruhi oleh variabel lainnya yang tidak terdapat di dalam penelitian ini. Kewirausahaan bricolage mempunyai pengaruh sebesar $76,1 \%$ terhadap kewirausahaan berkelanjutan, sisanya sebesar 23,9\% dipengaruhi variabel lain yang tidak terdapat di dalam penelitian ini.

Tabel 4. 12

Tabel Koefisien Determinasi $\left(\mathbf{R}^{2}\right)$

\begin{tabular}{|c|c|}
\hline Variabel & Hasil \\
\hline Kewirausahaan Berkelanjutan & 0,761 \\
\hline Kewirausahan Bricolage & 0,831 \\
\hline
\end{tabular}

\section{Path Coefficients}

Hasil dari Path coefficients menunjukkan bahwa hubungan antara variabel memiliki hubungan yang positif

Tabel 4.13

Tabel Path Coefficients

\begin{tabular}{|l|c|}
\hline \multicolumn{1}{|c|}{ Variabel } & Path Coefficients \\
\hline Orientasi Kewirausahaan $\rightarrow$ Kewirausahaan Bricolage & 0,458 \\
\hline Orientasi Berkelanjutan $\rightarrow$ Kewirausahaan Bricolage & 0,490 \\
\hline Kewirausahaan Bricolage $\rightarrow$ Kewirausahaan Berkelanjutan & 0,289 \\
\hline $\begin{array}{l}\text { Orientasi Kewirausahaan } \rightarrow \text { Kewirausahaan Bricolage } \rightarrow \\
\text { Kewirausahaan Berkelanjutan }\end{array}$ & 0,132 \\
\hline $\begin{array}{l}\text { Orientasi Berkelanjutan } \rightarrow \text { Kewirausahaan Bricolage } \rightarrow \\
\text { Kewirausahaan Berkelanjutan }\end{array}$ & 0,141 \\
\hline
\end{tabular}

\section{Analisis Mediasi}

Berdasarkan hasil pengujian analisis mediasi dengan menggunakan metode bootstrapping dari SmartPLS menunjukkan bahwa variabel kewirausahaan bricolage secara positif memediasi orientasi kewirausahaan terhadap kewirausahaan berkelanjutan tetapi tidak signifikan karena nilai t-statistics 1,754 lebih kecil dari 1,96 dan p-values 0,080 lebih besar dari 0,05. Berdasarkan hal tersebut maka dapat dijelaskan bahwa kewirausahaan bricolage memediasi secara partial orientasi kewirausahaan terhadap kewirausahaan berkelanjutan.

Variabel kewirausahaan bricolage juga secara positif memediasi orientasi berkelanjutan terhadap kewirausahaan berkelanjutan tetapi tidak signifikan karena nilai $t$-statistics 1,891 lebih kecil dari 1,96 dan nilai p-values 0,059 lebih besar dari 0,05. Maka, berdasarkan hal tersebut dijelaskan kewirausahaan bricolage juga memediasi secara partial orientasi kewirausahaan terhadap kewirausahaan berkelanjutan. 
Uji hipotesis

Tabel 4. 1

Hasil Bootsrapping

\begin{tabular}{|l|c|c|c|c|}
\hline \multicolumn{1}{|c|}{ Hipotesis } & $\begin{array}{c}\text { Original } \\
\text { Sampel }\end{array}$ & $\begin{array}{c}\boldsymbol{t} \\
\text { statistics }\end{array}$ & $\begin{array}{c}\boldsymbol{P} \\
\text { values }\end{array}$ & Kesimpulan \\
\hline $\begin{array}{l}\text { Orientasi Kewirausahaan } \rightarrow \\
\text { Kewirausahaan Bricolage }\end{array}$ & 0,458 & 4,907 & 0,000 & Diterima \\
\hline $\begin{array}{l}\text { Orientasi Berkelanjutan } \rightarrow \\
\text { Kewirausahaan Bricolage }\end{array}$ & 0,490 & 5,337 & 0,000 & Diterima \\
\hline $\begin{array}{l}\text { Kewirausahaan Bricolage } \rightarrow \\
\text { Kewirausahaan Berkelanjutan }\end{array}$ & 0,289 & 2,018 & 0,044 & Diterima \\
\hline $\begin{array}{l}\text { Orientasi Kewirausahaan } \rightarrow \\
\text { Kewirausahaan Bricolage } \rightarrow \\
\text { Kewirausahaan Berkelanjutan }\end{array}$ & 0,132 & 1,754 & 0,080 & Ditolak \\
\hline $\begin{array}{l}\text { Orientasi Berkelanjutan } \rightarrow \\
\text { Kewirausahaan Bricolage } \rightarrow \\
\text { Kewirausahaan Berkelanjutan }\end{array}$ & 0,141 & 1,891 & 0,059 & Ditolak \\
\hline
\end{tabular}

Hasil dari pengujian hipotesis data dapat dijelaskan sebagai berikut:

a. H1: Orientasi kewirausahaan memiliki pengaruh positif dan signifikan terhadap kewirausahaan bricolage.

Uji hipotesis antara orientasi kewirausahaan terhadap kewirausahaan bricolage memiliki nilai $t$-statistics sebesar 4,907 > 1,96 dan nilai $p$-values sebesar $0,000<0,05$. Maka dapat dikatakan bahwa orientasi kewirausahaan memiliki pengaruh positif dan signifikan terhadap kewirausahaan bricolage sehingga dapat disimpulkan bahwa $\mathrm{H} 1$ diterima.

b. H2: Orientasi berkelanjutan memiliki pengaruh positif dan signifikan terhadap kewirausahaan bricolage.

Uji hipotesis antara orientasi berkelanjutan terhadap kewirausahaan bricolage memiliki nilai $t$-statistics sebesar 5,337 > 1,96 dan nilai $p$-values sebesar $0,000<0,05$. Maka dapat dikatakan bahwa orientasi berkelanjutan memiliki pengaruh positif dan signifikan terhadap kewirausahaan bricolage sehingga dapat disimpulkan bahwa $\mathrm{H} 2$ diterima.

c. H3: Kewirausahaan bricolage memiliki pengaruh positif dan signifikan terhadap kewirausahaan berkelanjutan.

Uji hipotesis antara kewirausahaan bricolage terhadap kewirausahaan berkelanjutan memiliki nilai $t$-statistics sebesar 2,018 >1,96 dan nilai $p$-values sebesar 0,044 < 0,05. Maka dapat dikatakan bahwa kewirausahaan bricolage memiliki pengaruh positif dan signifikan terhadap kewirausahaan berkelanjutan sehingga dapat disimpulkan bahwa H3 diterima.

d. H4: Kewirausahaan bricolage memiliki pengaruh positif dalam memediasi orientasi kewirausahaan terhadap kewirausahaan berkelanjutan secara partial namun tidak signifikan. 
Uji hipotesis antara orientasi kewirausahaan terhadap kewirausahaan berkelanjutan melalui mediasi kewirausahaan bricolage memiliki hasil original sampel positif sebesar 0,141 yang artinya terdapat pengaruh positif. Tetapi nilai $t$-statistics sebesar 1,754 >1,96 dan nilai $p$-values sebesar $0,080<0,05$ yang berarti terdapat pengaruh yang tidak signifikan, sehingga dapat disimpulkan bahwa H4 ditolak.

\section{e. H5: Kewirausahaan bricolage memiliki pengaruh positif dalam memediasi orientasi berkelanjutan terhadap kewirausahaan berkelanjutan secara partial namun tidak signifikan.}

Uji hipotesis antara orientasi berkelanjutan terhadap kewirausahaan berkelanjutan melalui mediasi kewirausahaan bricolage memiliki hasil original sampel positif sebesar 0,132 yang artinya terdapat pengaruh positif. Tetapi nilai $t$-statistics sebesar 1,891 > 1,96 dan nilai $p$-values sebesar $0,059<0,05$ yang berarti terdapat pengaruh yang tidak signifikan sehingga dapat disimpulkan bahwa H5 ditolak.

\section{KESIMPULAN}

Berdasarkan hasil dari pengelolahan dan analisis data yang sudah dilakukan maka dapat disimpulkan menjadi:

a. Orientasi kewirausahaan berpengaruh positif terhadap kewirausahaan bricolage di Indonesia.

b. Orientasi berkelanjutan berpengaruh positif terhadap kewirausahaan bricolage di Indonesia.

c. Kewirausahaan bricolage berpengaruh positif terhadap kewirausahaan berkelanjutan di Indonesia.

d. Kewirausahaan bricolage memiliki pengaruh positif dalam memediasi orientasi kewirausahaan terhadap kewirausahaan berkelanjutan di Indonesia secara partial namun tidak signifikan.

e. Kewirausahaan bricolage memiliki pengaruh positif dalam memediasi orientasi berkelanjutan terhadap kewirausahaan berkelanjutan di Indonesia secara partial namun tidak signifikan.

Saran. Dari hasil yang telah didapatkan dari penelitian ini, dengan begitu peneliti dapat memberikan saran yaitu:

a. Bagi para pemilik UKM perlu untuk meningkatkan perusahaan dengan memperhatikan orientasi kewirausahaan yang memanfaatkan kewirausahaan bricolage dalam memanfaatkan peluang untuk masa depan perusahaan. Serta menjadi wirausaha yang berorientasi pada keberlanjutan agar mencapai hasil yang baik dan mengarah pada kewirausahaan berkelanjutan.

b. Bagi penelitian selanjutnya disarankan untuk meneliti lebih lanjut mengenai hubungan kewirausahaan bricolage dalam memediasi orientasi berkelanjutan terhadap kewirausahaan berkelanjutan, karena terdapat hasil penelitian yang berbeda-beda.

c. Bagi penelitian selanjutnya disarankan agar dapat menambahkan variabel lain seperti orientasi teknologi dan kepercayaan, sehingga dapat menyempurnakan penelitian ini. 


\section{DAFTAR PUSTAKA}

Amit, R., Schoemaker, P. J. H., Journal, S. M., \& Jan, N. (1993). Strategic Assets and Organizational Rent Strategic Assets and Organizational Rent. December 2017. https://doi.org/10.1002/smj.4250140105

Anderson, B.S., Covin, J.G. and Slevin, D.P. (2009), "Understanding the relationship between entrepreneurial orientation and strategic learning: an empirical investigation", Strategic Entrepreneurship Journal,Vol.3No.3,pp.219-241

Baker, T., \& Nelson, R. E. (2005). Creating something from nothing: Resource construction through entrepreneurial bricolage. Administrative Science Quarterly, 50(3), 329-366. https://doi.org/10.2189/asqu.2005.50.3.329

Barney,J.(1991),“Firm resources and sustained competitive advantage”, Journal of Management, Vol.17 No.1, pp.99-120

Belz, F. M., \& Binder, J. K. (2015). Sustainable Entrepreneurship: A Convergent Process Model. https://doi.org/10.1002/bse.1887

Chandler, G.N. and Hanks, S.H. (1994), "Market attractiveness, resource-based capabilities, venture strategies, and venture performance", Journal of Business Venturing, Vol. 9 No. 4, pp.331-349.

Crals, E. and Vereeck, L. (2004), "Sustainable entrepreneurship in SMEs: theory and practice", Paper Presented at the $3^{\text {rd }}$ Global Conference on Environmental Justice, Copenhagen

Dacko, S.G., Claudy, M., Garcia, R. and Wilner, S.J. (2013), "Sustainability orientation as a driver of innovation within firms", Paper Presented at the ISPIM Conference Proceedings, Manchester

Dean, T. J., \& McMullen, J. S. (2007). Toward a theory of sustainable entrepreneurship: Reducing environmental degradation through entrepreneurial action. Journal of Business Venturing, 22(1), 50-76.

Gundry, L. K., Kickul, J. R., Griffiths, M. D., \& Bacq, S. C. (2011). Creating Social Change Out of Nothing: The Role of Entrepreneurial Bricolage in Social Entrepreneurs' Catalytic Innovations. In Advances in Entrepreneurship, Firm Emergence and Growth (Vol. 13, Issue 2011). Emerald Group Publishing Ltd. https://doi.org/10.1108/s10747540(2011)0000013005

Hooi, H.C., Ahmad, N.H., Amran, A. and Rahman, S.A. (2016), "The functional role of entrepreneurial orientation and entrepreneurial bricolage in ensuring sustainable entrepreneurship", Management Research Review, Vol. 39 No. 12, pp. 1616-1638.

IwanPrasodjo, Rita Amelinda, K. N. N. M. (2019). Sustainable Entrepreneurial Intention: The Perceived of Triple Bottom Line among Female Students. Jurnal Manajemen, 23(2), 168. https://doi.org/10.24912/jm.v23i2.472

Kellermanns, F., Walter, J., Crook, T. R., \& Kemmerer, B. (2014). The Resource-Based View in 
Entrepreneurship : A Content-Analytical Comparison of Researchers ' and Entrepreneurs ' Views. 1-23. https://doi.org/10.1111/jsbm. 12126

Kuckertz, A., \& Wagner, M. (2010). Journal of Business Venturing The in fl uence of sustainability orientation on entrepreneurial intentions - Investigating the role of business experience. Journal of Business Venturing, 25(5), 524-539. https://doi.org/10.1016/j.jbusvent.2009.09.001

Miller, D. (1983). The Correlates of Entrepreneurship in Three Types of Firms. May 2014.

Moorthy,M.K.,Yakob,P.,Chelliah,M.K.andArokiasamy,L.(2012),"DriversforMalaysianSMEs to Go Green", International Journal of Academic Research in Business and Social Sciences, Vol.2No.9,pp.74-86.

Penrose, E. G. (1959).The Theory of the Growth of the Firm. New York: Wiley.

Phillips, N. and Tracey, P. (2007), "Opportunity recognition, entrepreneurial capabilities and bricolage: connecting institutional theory and entrepreneurship in strategic organization", Strategic Organization, Vol. 5 No. 3, p. 313

Rahman, S. A., Amran, A., \& Ahmad, N. H. (2014). GrameenPhone : Creating a Win-Win at the Base of the Pyramid in Bangladesh. August, 41-53. https://doi.org/10.1002/joe

Schaltegger, S., \& Wagner, M. (2011). Sustainable Entrepreneurship and Sustainability Innovation: Categories and Interactions. 237(July 2010), 222-237.

Schaper, M. (2002). The challenge of environmental responsibility and sustainable development: Implications for SME and entrepreneurship academics. Radical Change in the World - Will SMEs Soar or Crash?; Umbruch Der Welt - KMU Vor Hohenflug Oder Absturz?, March, 525-534. http://cob.nmu.edu/amtmann/Lavras Course Materials/challenge of environmental responsibility and sustainable developement Implications for SME and entrepreneuship academics 2002.pdf

Sekaran, U., \& Bougie, R., (2016). Research Methods for Bussiness A Skill-Building Approach. Printer Trento Srl.

Shepherd, D. A. (2011). E T \& P The New Field of Entrepreneurship : Sustained" With "What Is to Be Developed.” 137-163. https://doi.org/10.1111/j.1540-6520.2010.00426.x

Silviasih. Franky Slamet, Denny Iskandar (2016). Pengaruh Orientasi Pasar Dan Orientasi Kewirausahaan Terhadap Kinerja Usaha Pada Pemilik Ukm Sektor Manufaktur Garmen Di Tanah Abang, Jakarta Pusat. Jurnal Ilmiah Manajemen Bisnis. Vol. 16, No. 1: 13-24

Stam, W. and Elfring, T. (2008), "Entrepreneurial orientation and new venture performance: the moderating role of intra-and extra industry social capital", Academy of Management Journal, Vol. 51 No. 1, pp. 97-111

Utama, L. and J.K. 2017. Pengaruh Kreatifitas Terhadap Kinerja Usaha Dengan Orientasi Kewirausahaan Sebagai Mediasi Pada Wirausaha di ITC Cempaka Mas. Conference on Managemant and Behavioral Studies. 
http://cmbs.untar.ac.id/images/prosiding/2017/p/Louis-utama-dan-jeremykristantonadi.pdf. Diakses Juni, 2020.

Wernerfelt,B.(1984),“A resource-based view of the firm”, Strategic Management Journal, Vol.5 No.2, pp.171-180

Wiklund, J. (2006), "The sustainability of the entrepreneurial orientation-performance relationship", Entrepreneurship and The Growth of Firms, Vol. 32 No. 1, pp. 141-155. 